\title{
A OBRA LITERÁRIA COMO EXPRESSÃO EXISTENCIAL DAS CONCEPÇÕES ONTOLÓGICAS DO SER DO HOMEM
}

\author{
Literary Narrative as Existential Expression of Ontological Conceptions about Being of Man
}

La Obra Literaria como Expresión de las Concepciones Ontológicas del Ser del Hombre

Ívena PÉrola do Amaral Santos

\begin{abstract}
Resumo: Este artigo tem por objetivo apresentar as dimensões ontológicas da existência humana desveladas pelo filósofo alemão Martin Heidegger. Em sua obra Ser e Tempo, Heidegger realiza uma analítica existencial pelo método fenomenológico, num movimento hermenêutico que visa alcançar, a partir da evidenciação da estrutura fundamental do Dasein - o ente humano -, o caminho que levará ao sentido do ser em geral. Nossa proposta segue um caminho inverso, pois, buscamos, a partir daquilo que constitui essencialmente o Dasein - em particular a temporalidade, a espacialidade, a abertura, a disposição, a corporeidade, o ser-no-mundo - aproximar das descobertas filosóficas heideggerianas os modos cotidianos que cada pessoa pode realizar e, com eles, constituir o seu próprio ser. Para realizarmos essa tarefa utilizamo-nos da narrativa literária por considerá-la aquilo que mais se aproxima das vivências afetivas experienciadas no dia-a-dia. Acompanhamos os relatos de Lya Luft em $O$ Rio do Meio e, por meio de uma descrição fenomenológica, buscamos uma diferente visão para a compreensão psicológica do existir humano concreto e contingente.
\end{abstract}

Palavras-chave: Martin Heidegger; Lya Luft; Experiência; Analítica Existencial; Fenomenologia.

Abstract: This article intends to present the ontological dimensions of human existence as told by the german philosopher Martin Heidegger. In his work Being and Time, Heidegger makes an existential analysis thru a phenomenological method, in an hermeneutic movement that it aims to reach, by an evidenciation of the fundamental structure of Dasein - the human creature -, the path that will take to the meaning of the being in general. Our purpose follows an opposite way, because we search from that witch essentially constitute Dasein - In particularly the temporality, the espaciality, the opening, the arrangement, the physicality, the being-in the-world - to approximate to the heideggerian philosophical discoveries the ways that each person can realize, and, with them build their own beings. To make this last task, we will use of the narrative literary through we believe to be the closest one to the one's we experience on our daily life. We follow Lya Luft's report in the Middle River and, through the phenomenological description; we search a different point of view for the psychological comprehension of the existence of the concrete and contingent human.

Keywords: Martin Heidegger; Lya Luft; Experience; Existential Analysis; Phenomenology.

Resumen: El propósito del artículo es presentar las dimensiones ontológicas de la existencia humana, reveladas por el filósofo alemán Martin Heidegger. En su obra Ser y Tiempo, Heidegger realiza un análisis existencial a través del método fenomenológico (un movimiento hermenéutico), que aspira alcanzar el ente humano a partir de la evidencia de la estructura fundamental del Dasein; un camino que llevará al sentido general del ser. Nuestra propuesta sigue en el camino inverso, pues, buscamos a partir de aquello que constituye esencialmente el Dasein- en particular la temporalidad, la espacialidad, la apertura, la disposición, la corporeidad, el ser en el mundo- aproximar los descubrimientos filosóficos heideggerianos, los modos cotidianos que cada persona puede realizar y con ellos constituir su propio ser. Para realizar esta tarea, utilizamos la narrativa literaria por considerarla el modo que más se aproxima a las vivencias afectivas experimentadas día a día. Acompañamos los relatos de Lya Luft en el Río del Medio y por intermedio de una descripción fenomenológica buscamos una visión diferente para la comprensión psicológica del existir humano concreto y contingente.

Palabras-clave: Martin Heidegger; Lya Luft; Experiencias; Análisis Existencial; Fenomenológica.

\section{Introdução}

Encontramos na obra literária o espelhamento de sentimentos, dúvidas, projetos, modos de relação e todo tipo de vivências que qualquer pessoa pode experimentar em sua existência.

Ficção ou baseada em relatos verídicos, referente àquele que escreve ou não, a obra literária é uma excelente fonte de conhecimento daquilo que constitui o ser do homem: que ele é e já está sempre numa relação de algum modo afinada.

Entretanto, a obra literária não deve, ela mesma, ser considerada como uma produção de conhecimento, mas, antes, como a manifestação experiencial de algo que sistemas filosóficos ou psicológicos objetivam teorizar.

Isso porque o escritor que se põe a fazer literatura, salvo algumas exceções, não está preocupado com as crenças filosóficas e/ou científicas que sustentam suas afirmações. 
Sua questão é a arte. A arte de escrever a respeito de experiências singulares. Emoção, e não razão. Em termos heideggerianos, o escritor utiliza-se da linguagem para mostrar (evidenciar, tornar presente) o existir humano em sua concretude e de uma forma não-tematizada.

\section{Sobre o Ser do Homem na Perspectiva Heideggeriana}

Sob o ponto de vista filosófico (em conformidade a Heidegger), a definição sobre o ser do homem, citada acima, como aquele que é e está sempre numa relação e desde já num modo da afinação, quer dizer:

1. que o ser do homem, estruturalmente, é um estarcom os outros e consigo próprio e junto-a tudo o que existe no mundo, seja concreto ou imaginado;

2. que o ser-em-relação pressupõe o homem ser sua própria abertura, participando dela;

3. que o encontro dado na abertura é sempre de alguma maneira definido pela disposição (humor) em que o homem se encontra;

4. que essa disposição possibilita ao homem compreender o mundo e a si próprio, atribuindo significados, anteriores a qualquer reflexão;

5. que na compreensão de si o homem se projeta nas possibilidades com as quais encontra na abertura, essencializando sua existência nos particulares modos de ser;

6. que faz parte da estrutura do homem ter corpo para efetivar relações e atualizar possibilidades, corpo este que transcende a matéria físico-fisiológica e alcança o caráter de dimensão existencial.

Para se chegar ao ser que constitui o homem e explicitar os elementos estruturais que fundamentam sua expressão cotidiana, a filosofia necessitou partir daquilo que está no ôntico, ou seja, dos modos concretos do homem construir sua existência. Em contrapartida, é exatamente na concretização ôntica que vemos comprovadas as abstrações filosóficas que alcançam a estrutura e o fundamento ontológicos do existir humano, denominados por Heidegger como Dasein.

Assim, o relato literário torna-se o testemunho do dizer filosófico-científico. Ou seja, a expressão singular presente na literatura é um recorte da realidade - entendida como as experiências e significações dadas pelo estar-nomundo - e possibilita a comprovação ôntica das análises e reflexões ontológicas e teoréticas.

\section{Da Necessidade de uma Ciência Própria ao Ser do Homem}

Um pequeno aparte, antes de prosseguirmos. Há pelo menos duas maneiras de nos relacionarmos com a exis- tencialidade humana: uma com o objetivo de desvendá-la estruturalmente (o que é feito pela filosofia) e a outra com o intuito de intervir (como é o caso das ciências humanas). Para uma intervenção de caráter psicológico - nossa área de atuação - partilhamos da opinião de que ainda nos falta uma teorização, e conseqüentemente uma prática, apropriadas ao modo específico de ser do homem. Isso significa que o modelo de ciência atualmente oferecido e executado dá conta de uma parcela do que se refere ao homem. Necessitamos de uma ciência que alcance o homem em sua humanidade, naquilo que lhe é mais próprio. Essa nova ciência requer um fundamento igualmente original. Encontramos esse fundamento no pensamento de Martin Heidegger. Sabemos que outros teóricos (Binswanger 1962, 1973; Boss 1963, 1971) o utilizaram antes, porém não passaram pelo crivo avaliativo do próprio Heidegger. Portanto, uma ciência específica para lidar com o humano ainda está por ser construída. E essa construção necessita, primeiramente, de uma aproximação descritivo-fenomenológica entre aspectos ontológicos e ônticos da existência humana.

Tal descrição fenomenológica trata-se de um método próprio a uma sistematização científica, pois parte da constatação empírica. Contudo, não coincide com o método empírico tradicional porque não visa descrever as categorias e qualificações da situação dada, mas sim, busca descrever aquilo que faz da situação um fenômeno, isso é, a significação - enquanto doadora de sentido - que se mostra pela experiência do contexto que é observado. Em outros termos, é ir além da observação para alcançar a essência que constitui a situação, enquanto experiência propriamente humana.

\section{A Literatura como Exemplo do Existir Humano Concreto}

A aplicação desse método é o que propomos demonstrar neste trabalho e, para isso, tomaremos a literatura como fonte de experiências cotidianas. Nosso material será extraído de uma obra de Lya Luft, O Rio do Meio (1996), cujo conteúdo caracteriza-se como narrativo-ficcional, ou como a própria autora o denominou, "ensaios mais leves". O texto é composto por relatos que tanto podem estar referindo-se à autora como a outras pessoas, sem contudo nunca ser plenamente possível identificarmos o que pertence a ela, o que pertence a outro e o que é fruto de sua própria imaginação. Esse alerta a própria autora nos faz.

Este será, sobretudo, o meu livro das indagações: sobre as relações pessoais, a prodigiosa vida, o limite entre a fatalidade que nos tange e o momento de tomarmos nas mãos as rédeas do destino (Luft, 1996, p. 16).

É interessante a elaboração desse texto constituir-se mais de questionamentos do que de certezas, mostrando 
que a natureza humana é realmente um enigma. Mas, ainda que enigmático, o existir humano é ao mesmo tempo familiar, e isso é confirmado, por exemplo, pela facilidade com que o leitor pode se identificar com as experiências descritas pela autora. Essa identificação ocorre na afetividade, ou seja, há uma pré-compreensão da possibilidade do homem afetar-se pelo que lhe é dado nos diferentes relacionamentos que ele estabelece em seu dia-a-dia.

Em termos gerais, ao lermos as histórias contadas por Lya Luft é como se ela estivesse falando diretamente conosco, a nosso respeito mesmo ou sobre alguém que nos é próximo. Dessa experiência já podemos iniciar uma investigação sobre a presença da dimensão corporal nas relações. Podemos inferir que o relacionamento do leitor com a autora e com as personagens descritas é de proximidade. Esse sentimento de proximidade pressupõe espaço. E espaço é um lugar que um corpo pode ocupar.

Acontece que não estamos falando aqui de espaço físico, de dimensões objetivas, de um corpo visível. Estamos falando da experiência de estarmos em outro lugar, como se nos transportarmos para aquele mundo descrito nas páginas do livro, de nos tornarmos próximos a alguém por compartilharmos de suas colocações - sem que essa pessoa (a autora) sequer saiba objetivamente de nossa existência.

É essa capacidade de experienciar o mundo e a si mesmo, transcendendo o meramente objetivo ou subjetivo, que faz do homem um ente diferenciado dos demais entes da natureza. $\mathrm{O}$ ente humano não se resume à sua capacidade racional: não compreende o mundo e a si apenas numa relação quantitativa e qualitativa, definindo o que é o espaço, quanto ele mede, por quantas dimensões ele é formado, por exemplo. Também não se resume à atividade psicológica: não se percebe estando fisicamente sentado na cadeira ao mesmo tempo que viaja em pensamento pela narrativa. Tampouco o homem configura-se numa sucessão de atos neurofisiológicos: como se seu olho apenas percebesse as páginas do livro e seu cérebro processasse as informações codificadas como letras impressas, ativando a memória para torná-las inteligíveis a partir da identificação com aprendizagens anteriores.

Algumas Considerações Sobre os Existenciais Estruturais do Ente Humano (Dasein)

O que diferencia o homem dos demais entes da natureza é sua condição inerente de ser abertura. Ser abertura é, concomitantemente, estar-no-aberto. Isso significa que ao homem é sempre dada a possibilidade de estarjunto a tudo que não é ele próprio. Esse estar-junto tanto pode ser em relação a coisas presentes quanto ao que está ausente no momento. Assim, a indicação anterior de que nos transportamos para o mundo descrito no livro que lemos perde o sentido. Mas também não é estar na sala de leitura, fisicamente, e ao mesmo tempo estar no mundo imaginário da narração, em pensamento. Trata-se de estar integralmente junto à situação descrita no livro, numa diminuição da atenção sobre o que está concretamente presente, porém sem negar a existência da sala onde se está lendo.

O estar-aberto para tudo o que se diferencia de mim mesmo desdobra-se em estar-junto das coisas concretas que se modifica no estar-junto das coisas ausentes. Perto e longe, aqui e lá, que são categorias do espaço, perdem sua conceituação objetiva para serem percebidas existencialmente, quer dizer, na condição a priori de o homem ser-relação-com de maneiras diferentes e específicas.

Ao relacionar-se com o mundo que lhe é aberto na sua relação com o livro, o leitor trás para junto de si esse mundo não presente fisicamente. Esse tornar presente é corporal, na medida em que corporal não se limita ao corpo físico, mas indica o movimento que é meu, que eu faço e que a mim pertence. Eu e corpo não são duas instâncias que, unindo-se, formam o homem ${ }^{1}$. A motivação humana, que leva à mobilidade, é um traço da corporeidade.

E o que é motivação? Não se trata, absolutamente, de algo que impulsione o homem a comportar-se de determinada maneira. Não é uma força, uma causa ou uma razão que encontramos externa ao homem e que influencia seu agir. Aliás, motivação não é nem externa nem interna. Ela é inerente ao próprio existir humano. Vivenciada por meio de vários motivos particulares, a motivação está na própria relação em que o homem se encontra. Ela é a própria correspondência do homem com o mundo. Nessa correspondência, o homem compreende o mundo, compreende os motivos presentes no mundo, e move-se a partir de seus significados. Nesse sentido, a motivação é determinante das escolhas que o homem faz, pois "refere-se à existência do homem no mundo como um ente que age, que tem experiências" (Heidegger, 2001 [1987], p. 51).

As escolhas, entendidas como o sentido que a pessoa dá ao seu existir, estão determinadas, por sua vez, pelo modo como essa pessoa interpela e se deixa interpelar na relação com o mundo. Por isso, as escolhas, na maioria das vezes, não são refletidas. Antes, já são definidas pela atmosfera, que podemos traduzir como sentimentos, emoções, interesses, desejos, vontades e todo tipo de vinculação que o homem pode realizar no seu cotidiano. E todas elas pressupõem corporeidade. É a dimensão corporal - não igualada ao corpo físico - que permite a

\footnotetext{
A indissociabilidade entre corpo e consciência também é encontrada, por exemplo, em Maurice Merleau-Ponty (Fenomenologia da Percepção, 1945). O filósofo francês considera a existência humana justamente como uma consciência encarnada, conjugada ao mundo pela percepção. Em $O$ Visível e o Invisível (1964), Merleau-Ponty continua suas análises a respeito da superação da dicotomia sujeito/objeto, ou homem/ mundo, tratando mais propriamente da abertura humana para o Ser. Reconhecemos nesse autor fortes influências de Heidegger, ainda que sua fenomenologia difira deste, seja enquanto método, seja por seus objetivos.
} 
pessoa movimentar-se em aproximação ou afastamento em relação com aquilo que, de alguma maneira, vinculase. Afastamento e aproximação deixam de ser referências espaciais, objetivamente mensuráveis, para se tornar experiência espacial, melhor dizendo, "uma orientação de acordo com as coisas no espaço” (Heidegger, 2001 [1987], p. 39).

\section{A Analítica Existencial Heideggeriana e as Experiências Cotidianas Descritas por Lya Luft: Uma Aproximação}

Lya Luft questiona: "talvez se despreze demais o cotidiano. Quem sabe está nele o verdadeiro mistério, nesse acumular coisas, regras, gestos e convenções, para organizar a vida diária?” (Luft, 1996, p. 39).

O cotidiano é o próprio construir a história de cada um. Ele representa o lugar onde organizamos tudo o que está ao nosso redor, e essa organização é estabelecida pelas experiências vividas com aquilo que se apresenta nesse espaço. São pelas significações dadas na experiência que se torna possível elaborar regras e estabelecer convenções, por exemplo.

O cotidiano também se caracteriza como temporal. Na organização diária é possível ter tempo para algumas coisas e não ter tempo para outras. Acumular coisas, por exemplo, pode denotar tempo. Assim, a história cotidiana de uma pessoa vai se formando pelo seu movimentar no mundo, onde opta por demorar-se junto a determinadas coisas - concretas ou abstratas - em detrimento de outras que se tornam privadas do tempo pertencente a essa pessoa.

Estar disponível para algumas experiências e indisponível para outras é o modo como o homem utiliza seu tempo, este inerente ao próprio existir e sempre presente. Ter tempo para algo e não ter tempo para outra coisa são movimentos singulares permeados pelos afetos. São, na citação de Lya Luft, os gestos. Os gestos não são apenas as expressões faciais, as mímicas ou qualquer outro tipo de linguagem corporal. Os gestos são toda atividade - corporal (física) e corpórea (existencial) - pertencente ao homem e que lhe permite relacionar-se com o mundo. As expressões são um modo de interpretar os gestos. Os gestos, em sua essência, são os movimentos da existência humana. E a existência humana, essencialmente, é experiência.

Quando Lya Luft alerta que o cotidiano não deve ser desprezado, remete-nos à reflexão quanto à forma como os gestos diários têm sido interpretados e tratados. Há, atualmente, uma apologia à felicidade e ao sucesso profissional. Contudo, a exigência que a sociedade faz quanto a esses atributos a serem conquistados pelo homem, em vez de promover um estado de serenidade, traz o aniquilamento do si mesmo mais próprio e um afastamento da verdadeira compreensão da essência humana.
Assim Lya Luft revela, nesta descrição denunciadora, a maneira como o movimento genuíno da existência humana vem sendo cerceado cada vez mais constantemente:

O que sabemos é que é preciso 'ser feliz'. Banalizamos a felicidade como ausência de problemas, um estado de idiotia e irresponsabilidade, uma incessante animação obtida por recursos mágicos.

Ter felicidade (como se tem um bom carro e emprego garantido) tornou-se um pesado encargo. Usamos e malbaratamos palavras como 'espaço', 'direito', 'curtir'. Ninguém mais pode se deprimir, em cada esquina ou página de jornal e revista vendem-nos receitas para uma euforia permanente e artificial. Estarmos um dia mais recolhidas parece suspeito. "Como ser feliz (ou rico ou bem-sucedido ou magro ou musculoso) em doze lições a preço módico" é o grande chamamento (Luft, 1996, p. 63).

Isso é o esquecimento. O grande chamamento, genuinamente, é a consciência de si. Consciência no sentido de compreender vivencialmente a condição finita e temporal do homem, o que torna-o responsável por si mesmo. Essa responsabilidade expressa-se no ter de assumir o seu "poder-ser-si-mesmo, em sentido próprio" (Heidegger, 1996 [1927], §54, p. 52). Isso quer dizer que ao homem cabe deixar sua própria singularidade mostrar-se.

A consciência é uma voz que chama o Dasein à sua propriedade. Esta voz, contudo, não possui qualquer conotação legal ou moral. Ela visa apenas resgatar o Dasein da cotidianeidade mediana em que está imerso, fazendo-se consciente de sua condição originária de finitude, cuidando de seu poder-ser à luz do não-mais-estar-aí. Esta voz só consegue se fazer ouvir através da abertura proporcionada pela angústia primordial. Ou, conforme Heidegger resume, "a consciência é o clamor da cura [Sorge] que, a partir da estranheza do ser-no-mundo, conclama a pre-sença [Dasein] para assumir o seu poder ser e estar em débito mais próprio” (Heidegger: 1996 [1927], § 59, p. 77).

Mas, em tempos modernos não há lugar para a angústia. Não há lugar para o reconhecimento de que a existência humana é sem fundamento. E na tentativa de esquecerse de si mesma - enquanto seu próprio fundamento - a pessoa aceita a voz impessoal do mundo, que diz a ela que o melhor é aplacar os sentimentos considerados negativos e cultivar aqueles que a farão adaptar-se às exigências cotidianas. Tal cultivo só pode ser alcançado de maneira artificial, às custas dos milagres da medicina.

Não queremos com isso dizer que a medicina é prejudicial. Seus progressos e descobertas são francamente bem-vindos quando o assunto é cuidar da dor física. Mas quando o assunto é - digamos assim - espiritual, a salvação não está na busca pelo equilíbrio da composição química do cérebro, mas na apropriação das possibilidades que fazem o existir singular.

Todavia, não é apenas pelo consumo de drogas antidepressivas que se tenta resolver as chamadas crises existenciais. As pessoas também têm buscado no culto 
ao corpo um caminho para resolver as questões que pertencem propriamente à existência como um todo. Aliás, outra apologia presente nos dias atuais refere-se à beleza estética. Esse caminho igualmente aniquila o ser, pois o iguala à aparência, impedindo-o de revelar-se por sua essência.

Atualmente, pessoas bastante jovens preocupam-se exageradamente em manter o corpo dentro dos padrões considerados perfeitos, tentando prevenir antes do tempo necessário o seu envelhecimento. Meninas passam creme anti-rugas antes de tê-las, por exemplo. Aliás, o envelhecimento cada vez mais vem se transformando num tabu. Mas, como Lya Luft assinala, preocupar-se com o externo traz a perda de nunca desenvolver plenamente aquilo que faz de nós humanos: nossa própria história vivencial.

Conheço as mulheres ocas: um dia foram meninas plenas da semente do seu destino, mas em algum momento a perderam, ou lhes foi subtraída. Desumanizadas, desmaterializadas, não riem muito para não criar rugas, não amamentam para que os seios não caiam. Afivelam uma sobre a outra máscaras cada vez mais inexpressivas em que os anos, os amores, as perdas e a ternura não deixaram marcas (Luft, 1996, p. 56).

Menopausa, netos, rugas, cintura menos fina assombram algumas mulheres de forma dramática.

É um desperdício atormentar-se com o que nem o melhor cirurgião pode atrasar em definitivo, ir muito além de discretas correções para melhorar a auto-estima, construindo - da sua própria destruição - uma máscara ou caricatura do rosto natural (Luft, 1996, p. 109).

Ao preocupar-se seja com a aparência ou com a essência, de qualquer maneira a pessoa está escrevendo sua própria história. A diferença está no significado que cada correspondência traz em relação à solicitação pela qual a pessoa é interpelada. Como nos ensina Heidegger, " a solicitação em geral exige em cada caso um corresponder de alguma coisa. A esse corresponder pertencem também, como privações, o não corresponder e o não poder corresponder" (Heidegger, 2001 [1987], p. 167).

Assim, ao não aceitar-se como ser-para-o-fim, a pessoa está correspondendo à solicitação do envelhecer no modo da privação, ou seja, no privar-se dessa experiência. Mas, na medida em que o corpo pode ser utilizado como instrumento para esquecer-se de si mesmo, há também a possibilidade de uma doença corporal resgatar essa consciência de ser-para-a-morte, alterando a relação da pessoa com sua própria vida. "Essa é uma das estranhas vantagens de saber que se vai morrer: a vida se mostra em todo o seu esplendor, e nos faz sentir a urgência - não de devorá-la, mas de vivê-la melhor" (Luft, 1996, p. 122-123).

Lya Luft conta-nos sobre um amigo que está com AIDS: "ele, portador e já doente, alguns dias queixa-se da luta contra o corpo que enfraquece e dói; outras vezes, comenta os projetos, os trabalhos" (Luft, 1996, p. 123). Esse re- lato é em si mesmo bastante elucidativo na diferença de entendimento do corpo enquanto organismo e enquanto experiência. Mesmo doente, o amigo de Lya Luft tem projetos. Mesmo morrendo, ele permanece junto àquilo que lhe interessa, que lhe dá motivos para continuar traçando um sentido para sua vida. E é possível pressupormos que a sua vida lhe é muito mais própria porque está permeada pela morte.

Cuidar de seus relacionamentos é a tarefa do homem. Isso significa estar atento para o modo como as vinculações ocorrem a cada dia. Senão, num dia qualquer, percebe-se que o tempo passou e que tudo o que foi construído durante esse tempo foi desperdiçado por não ter sido realizado com o envolvimento que toda relação necessita. Um envolvimento no qual o ser da pessoa está, a todo momento, presente. Um envolvimento que realmente promove o encontro. Como por exemplo, nas relações interpessoais.

Estamos destinados a viver aos pares, e não há de ser apenas pela sobrevivência da espécie. Algumas pessoas vivem bem sozinhas, preenchem a vida com profissão e amizades. A maioria, eu acho, deseja uma presença mais permanente, alguém que as ame e estimule, que as escute, que precise delas, um interlocutor.

Mas as relações humanas são em geral tortuosas. Mulheres cheias de ardor e ternura entregam-se a ligações que aos poucos as vão esvaziando: tornam-se amargas, secas e difíceis de conviver. Mulheres que pouco esperavam desabrocham ao toque de quem sabe amá-las e consegue compreendê-las.

Mas também homens entram em relações da quais esperavam ternura e companheirismo e vão se isolando, lançam-se no trabalho ou em aventuras para se protegerem da dor; a bela mulher por quem tinham se apaixonado em breve se transformou numa matrona queixosa ou alguém distraído que pouco tem a ver com eles (Luft, 1996, p. 51-52).

Quando e por que motivo, se se amavam, o outro deixou de ter encanto - e tudo o que se quer é o diferente, o arrepio de uma outra primeira vez, o cheiro de uma nova pele, outro tipo de proximidade?

Quem errou, em que momento? Qual a primeira palavra inadequada, quando o primeiro bocejo de tédio, onde a primeira incompreensão grave - e por que foi impossível entender-se e recomeçar, partindo desse novo entendimento? De repente percebemos: estamos distantes, e desinteressados (Luft, 1996, p. 88).

O que dizer desse desencontro? Nele está presente todo o projeto de ser de duas pessoas. Há muita expectativa sobre o outro, num pedido de que o outro seja o fundamento de si. Mas o outro também requer um fundamento que, não sabendo encontrá-lo em si mesmo, vai buscar fora, no mundo. Lá também não o encontra, pois as respostas que o mundo dá apenas adiam o que de fato seria a solução: o encontro consigo mesmo antes de querer encontrar-se com o outro. 
No encontro genuíno², o outro não é restringido às suas características de personalidade ou à sua constituição corporal. As modificações que se dão ao longo do tempo, inevitáveis e infalíveis - especialmente com relação ao aspecto físico - não tornam-se obstáculos ou motivos para que se distanciem um do outro.

Logo, tanto o encontro como o desencontro dão o tom do movimento existencial executado pela pessoa. Nele concorrem todas as dimensões que caracterizam a experiência humana: o tempo, o espaço, o corpo, o relacionar-se, os afetos, a ação. Esse movimento evidencia quem é essa pessoa; ele nos dá a sua identidade. Reconhecer com que modos essa identidade se forma e abri-la para o paciente é a primeira tarefa do psicólogo no exercício de uma análise da existência factual. "Trata-se aqui, primeiramente, de observar e refletir mais profundamente sobre o que interpela em primeiro lugar o homem existente - a saber, o mundo em que ele está cotidianamente" (Heidegger, 2001 [1987], p. 167).

Como última referência a Lya Luft, resta-nos concordar com sua colocação de que no cotidiano está o mistério. O mistério consiste em como nossas orientações e relações são estabelecidas no mundo. Esse é o horizonte no qual a psicologia, no exercício psicoterapêutico de uma análise do existir, deve deter-se para compreender verdadeiramente o homem como um ente indivisível e indissociável.

\section{Referências bibliográficas}

Binswanger, L. (1962). Psiquiatria Existencial, Santiago, Universitária.

Binswanger, L. (1973). Artículos y Conferencias Escogidas, Madrid, Gredos.

Boss, M. (1963). Psychoanalysis and Daseinsanalysis, New York, Basic Books.

\footnotetext{
2 Uma reflexão sobre o encontro genuíno pode ser encontrada também, por exemplo, em Martin Buber. Sua principal obra, Eu e Tu (1977), traz a preocupação de Buber com a necessidade de uma disponibilidade mútua entre cada indivíduo, existente apenas pelo diálogo. Para esse autor, os encontros se dão gratuitamente, e têm como finalidade última o encontro do eu com o tu eterno, isto é, o Deus Criador. Essa é uma das diferenças encontradas entre Buber e Heidegger: o aspecto cristão ausente no pensamento do segundo filósofo. No que diz respeito à consideração à vida humana concreta, ambos são coincidentes, porém, Buber não pretende desenvolver uma ontologia, ao passo que Heidegger sim. Essa é, aliás, uma das críticas de Buber a Heidegger. Segundo Buber, a analítica existencial heideggeriana não oferece subsídios para uma compreensão antropológica da vida humana. Entretanto, como acreditamos que o pensamento heideggeriano possibilita essa compreensão - opinião já emitida por Binswanger e por Boss -, optamos por seguir apenas seus ensinamentos, sem realizar paralelos com outros autores, apesar de reconhecermos a importância deles.
}

Boss, M. (1971). Existential Foundations of Medicine and Psychology, New Jersey, Jason Aronson.

Buber, M. (1977). Eu e Tu, São Paulo, Moraes.

Giles, T. R. (1989). História do Existencialismo e da Fenomenologia, São Paulo, E.P.U.

Heidegger, M. (1995). Ser e Tempo - Parte I, Petrópolis, Vozes.

Heidegger, M. (1996). Ser e Tempo - Parte II, Petrópolis, Vozes.

Heidegger, M. (2001). Os Seminários de Zollikon, Petrópolis, Vozes.

Luft, L. (1996). O Rio do Meio, São Paulo, Mandarim.

Merleau-Ponty, M. (1994). Fenomenologia da Percepção, São Paulo, Martins Fontes.

Merleau-Ponty, M. (2003). O Visível e o Invisível, São Paulo, Perspectiva.

Ívena Pérola do Amaral Santos - Doutoranda em Psicologia pela Universidade de Brasília, Mestre em Psicologia Clínica pela Pontifícia Universidade Católica de São Paulo, Formada em Psicologia Fenomenológico-Existencial pelo Instituto SOBRAPHE (Sociedade Brasileira de Psicologia Humanista e Existencial-SP), Especializada em Gestalt-terapia pela Escola Paulista de Psicologia Aplicada (EPPA-SP) e pelo Instituto Piéron (SP), Professora do curso de Psicologia da Universidade Paulista (Unip-DF) e da Faculdade Alvorada (DF). Email: veveip@gmail.com. 